\title{
THE NRC-AMS CONFERENCE ON TRAINING IN APPLIED MATHEMATICS
}

This is a summary report on a conference on training in applied mathematics which was held under the joint sponsorship of the $\mathrm{Na}$ tional Research Council and the American Mathematical Society in conjunction with the latter's regular meeting at Columbia University on 22-24 October 1953. The conference was organized as part of the current Survey of Training and Research in Applied Mathematics conducted by the Mathematics Division of the National Research Council under provisions made by the National Science Foundation jointly with the Army's Office of Ordnance Research, the Office of Naval Research, and the Office of Scientific Research of the Air Force. Complete proceedings are being submitted to the National Science Foundation as a report under the Survey contract. Inquiries regarding the availability of copies should be sent to Dr. L. W. Cohen, Program Director for Mathematical Sciences, National Science Foundation, Washington 25, D. C., prior to 30 April 1954. Final arrangements for distribution will depend on the anticipated demand.

Purpose and agenda. From the beginning the plans for the Survey included as an important part the arrangement of one or several conferences on the various phases of training and research in applied mathematics. Breadth of coverage and the effective presentation of all relevant viewpoints were to be the primary aim of these meetings regardless of whether or not general agreement would ultimately be attained. Two conferences appeared to be indicated, one of them to present characteristic current research to a large audience of mathematicians, illustrating particularly active sectors of the front along which mathematics interacts today with other scientific disciplines, and the other one to subject the possible patterns of training applied mathematicians to an intensive discussion by a smaller group of persons specifically interested and concerned. The Conference on Training in Applied Mathematics was arranged to serve this latter purpose, bringing together both producers and consumers of applied mathematicians and having them compare their ideas, experiences, and expectations.

In accordance with this plan the meeting was broken down into two parts, during the first of which training programs were reviewed by outstanding faculty members from universities which have made major efforts to provide a home for applied mathematics on their 
campus, while during the second part leaders from governmental and industrial organizations discussed the present and the anticipated future role played by mathematicians in their establishments. These two parts were separated by a group of three invited addresses presenting characteristic aspects of the education of applied mathematicians in certain European countries, and a particularly effective summarizing address by Dr. Thornton C. Fry of the Bell Telephone Company concluded the conference.

Summary of discussions. The conference certainly achieved the aim of being comprehensive, and very little, if anything at all, was left unsaid which can reasonably be said about applied mathematics and applied mathematicians. Yet in building up from a somewhat confused and groping start to the firm final summary, gathering sense and direction as it went along, the work of the conference managed to reveal a broad, common fabric of recognized trends, concordant ideas, and established objectives. It is this which gave the conference its real impact and significance.

The American applied mathematical scene as we see it today is a product of World War II. It has since been kept from falling apart by the research supporting efforts of the Federal Government, and there is as yet little indication of a change. Whatever the appearance that current interest in applied mathematics merely reflects the desire of mathematicians to capitalize on the availability of such funds, there is a general conviction that this interest is really and honestly due to the wealth of substantial problems which confront us especially in the production of equipment and organizations capable of meeting the challenge of combat conditions. These are problems where the mathematician can make unique and effective contributions since tradition and experience are of ten lacking or inaccessible; moreover they are of real mathematical significance, engaging the best he has to offer. Thus, the military climate of the war and cold war years has catalyzed a situation which civilian and commercial competition would have taken yet another decade or more to produce.

The needs of the Federal Government. In keeping with this state of affairs, the Federal Government sets at present the pace for the demand of applied mathematicians. Numerous specifically mathematical positions, ranging from the lower rungs to the very top of the Civil Service ladder, have been established in Federal Departments and in the laboratories they operate. To these must be added the jobs of similar nature, existing in laboratories operated under contract by outside agencies for work on Government problems. Gov- 
ernment spokesmen could therefore be particularly specific as to what must be required and expected of the applied mathematician. First and foremost he must be a good mathematician, sound and wellrounded of training. Mathematical statistics and probability should in every case be part of his background. Aside from this it is almost immaterial whether or not he is skilled in any one particular technique. If he needs it, he can learn it on the job, while this would not be a favorable environment for extending his fundamental mathematical background. In addition he will need substantial knowledge in some other related fields of science, again on a sufficiently basic level so that he is not only able to handle the problems of today in his field but to learn and to develop what he may need in analyzing and designing the mechanisms and systems yet to be realized in the course of his life-time. A second group of prerequisites can be gathered under the heading of technical geniality, used by one of the speakers: A ready interest in other peoples' problems, the ability to work as member of a team, effectiveness and clarity in the communication of ideas. It is inevitable that any coordinated scientific effort, mathematical or otherwise, brings with it the responsibility for other persons' work or for the management of funds or programs. Hence, a certain amount of executive ability, be it inborn or acquired,- of trustworthiness, responsibility, and common sense, are often demanded.

One of the most significant factors affecting the demand for mathematicians at first in Government agencies and now also in industry is the emergence of the high-speed automatic computer. It has enhanced the usefulness of the applied mathematician in his traditional role of carrying out preliminary analyses of proposed systems by permitting a higher level of complexity in the mathematical models which can be subjected to final numerical evaluation. Even more important is the growing need for new mathematical insight and methods to insure the effective use of such machines. This creates a demand for an "applied" sort of mathematician much deeper grounded in "pure" mathematics than his traditional predecessor ever was. The effective use, in particular, of the large-scale electronic computers includes the burgeoning science of numerical simulation in which quite abstract phases of mathematics, and therefore the mathematicians who are experts in them, are proving very useful.

While much of this is equally true of the situation in industry, at least in a qualitative way, it is characteristic for the Government that there is a sizeable number of jobs primarily concerned with the administration rather than the actual performance of mathematical re- 
search. It should be a matter of concern to the entire mathematical community that competent mathematicians, possessing the necessary additional abilities, be available to fill, in particular, the positions of this type on the policy level: the Program Director for Mathematics of the National Science Foundation, the Mathematical Sciences Divisions and Mathematics Branches in the three military Offices of Research, and the Mathematics Division of the National Bureau of Standards. Beyond these there are positions, such as the Science Director of the Office of Naval Research, the Director of the Weapons Systems Evaluation Group, and others, for which mathematicians are eligible but in competition with representatives of other scientific fields. In all of them there is added to the duties of program administration the challenging and important assignment of creating, within the latitude allowed by Civil Service regulations, an acceptable environment in which a staff of competent scientists can work.

Industrial demands. With some notable exceptions, practically all of the mathematical work in industrial laboratories is done by engineers, physicists, and chemists who command a knowledge of the theoretical aspects of their fields. The more extensive employment in such environments of people who are trained and act primarily as mathematicians is generally considered a matter of the future whose potential benefits are freely acknowledged. In the meantime, however, there exists in industry nothing like the elaborate system of welldefined mathematical positions now found in the Federal Government. Mathematics majors, hired fresh out of college, are generally not slated by their subsequent training for a career as mathematicians but they use their mathematical background to get a good start in one or the other engineering specialty. The unbridged gap of understanding between the mathematician and the practicing scientist, due to the insufficient knowledge which each has of the other's field, was principally held responsible for this continued dearth of career mathematicians in industry. As of now the theoretically inclined scientist is therefore called upon to acquire such mathematical skills as may be needed, mostly on an ad hoc basis, yet occasionally to the point where he becomes a mathematician in all but the name.

It is recognized that this approach is reaching the point of diminishing returns as it becomes profitable to bring into play mathematical modes of thought and analysis which lie beyond the specifically devised ad hoc techniques. The availability of electronic computers will bring about a truly explosive acceleration in this process, and, unless it is not too late even now, there is certainly no time to lose in making adequate preparations. The IBM Company has now installed 
all over the country more than 1,000 electronic punched card machines (Type 604), each requiring at least one competent mathematician to operate, and about 100 Card Programmed Calculators, each requiring a team of from three to six mathematicians, if they are to be effectively used. The type of applied mathematician, moreover, for which these installations are looking, is not the junior technician specifically drilled in coding problems; it is the same competent, wellrounded mathematician for whom the Government jobs are competing. Thus, these IBM installations alone are currently opening up roughly 1,500 new jobs for applied mathematicians with graduate training.

The most notable of the exceptions mentioned at the beginning is the Mathematical Research Department of the Bell Telephone Laboratories which can now look back on about 25 years of fruitful cooperation between mathematicians and engineers. Even with every consideration being given to the fact that the problems of communications engineering are particularly accessible to a broadly based mathematical approach, the experiences which are reflected in the operation of this group today are particularly relevant at the present time.

Training programs. It is impossible to find a natural dividing line between pure and applied mathematics. Just as the various branches of mathematics interact with each other so they interact with other scientific disciplines, deriving inspiration and often motivation from both. Has Boolean algebra, it was asked, become a different subject because it was discovered to be of use in the design of switching circuits? Hence, no such line should be drawn artificially in the curriculum of prospective mathematicians. Applied mathematics must therefore be considered primarily a matter of attitude and motivation; the designation of secular in contrast to monastic mathematics was suggested as doing more justice to the situation than the traditional pure and applied.

The discussions were mostly concerned with graduate training, driving home in varied ways the salient point that its aim must be the formation of good general mathematicians who have at the same time a broad knowledge in some other related sciences. In the considerable variety of programs which were presented as having been fashioned towards these ends, there were two points about which prevailing opinions seem to be particularly diverse. The first of these concerns the relative size and administrative position of programs training a type of mathematician who is neither urged nor desires to learn what significance his subject has in its relation to other scientific disciplines. The second one is that of establishing the amount of 
experience in other scientific fields which should minimally be demanded and maximally be provided for. The adopted or proposed solutions to these problems determine the spectral structure in the broad-band concept of applied mathematician: There is the mathematical engineer, described as a man of action, able to deal with practical situations without waiting indefinitely until all conceivable data are in and the theory has reached academic perfection, and who more likely than not has topped off his formal education by participating in a research project involving experimental work. There is the applied mathematical dreamer and tinkerer who constructs his ingenious models to capture the thoughts the engineers will be thinking three or five years hence. There is the mathematician who uses long unsolved problems of other sciences to give both them and mathematics a new lively turn; the mathematical consultant with his broadly integrated knowledge and research experience; and many others.

To the extent that this variety of approaches is due to the flexibility of our institutions of higher learning in adapting their applied mathematics programs to their particular environment and to their individual administrative structure, this is all to the good. A continued effort of cooperation will be needed, however, to eliminate from this picture everything which is the result of adapting to misapprehensions about the demands of the future as well as to the traditional prejudices that the pure takes precedence over the applied and that the extensive contact with other sciences weakens the mathematical fibre.

The greatest single difficulty, generally experienced, is that of attracting good students in sufficient number. Numerous reasons were given for this lack of enthusiasm on the part of students to go into applied mathematics: Pure mathematics is taught more challengingly and, on the whole, by more inspiring teachers. A longer period of education and greater maturity are needed to do substantial work in applied mathematics while in the abstract phases a talented mathematician can gain recognition at an early age; on the other hand, engineering careers lead more quickly to higher salaries. Students generally do not know enough about the careers now opening up in applied mathematics; or again, they consider them unattractive because they are afraid that, by going into government or industry, they will lose their contact with living mathematics, and they know that it will be difficult to find academic jobs.

The discussion turned to the mathematical training of undergraduates as the proper point at which to attack this problem, either 
by the establishment of a specific applied mathematical curriculum paralleling the traditional one, or by adopting a single modernized and broadened course of study in mathematics which would produce a graduate equally qualified to pursue advanced work either in the pure or the applied direction. Either approach would make it possible to give the student a fair amount of information about the various professional careers which are open to him.

In the past most of the leaders in the field started out either as pure mathematicians, or as engineers and physicists, turning to applied mathematics only after having done substantial research in the field of their first interest. Similarly one might hope to see in the future the ranks of applied mathematicians unexpectedly strengthened by outstanding talents who are now working successfully along highly abstract lines. In the meantime, however, there are strong faculties in the purer branches of mathematics who are experiencing difficulty in finding suitable candidates to take care of the applied aspects.

Conclusion. In revealing large areas of agreement as far as facts, trends, and objectives are concerned, and in providing for a forthright expression of opinions where obvious differences existed, the conference has significantly contributed towards a clarification of the problems faced by the various groups who have a stake in the training of applied mathematicians. It reflected, to borrow the words of Thornton Fry, a growing appreciation by the monastic of the dignity of science in the market place, and by the secular of the dignity of pure thought. The tide is clearly running toward a cofraternity of mutual respect and mutual understanding, so necessary in our complete and interdependent world.

F. JOACHIM WeyL, Investigator, Committee on Training and Research in Applied Mathematics 